\title{
Assessment of Prevalence and Associated Factors of Preterm Birth at St Paul's Hospital Millennium Medical College, Addis Ababa, Ethiopia
}

\author{
Michael Tamene Haile \\ Neonatal nursing department, St Paul's Hospital Millennium Medical College, Addis Ababa, Ethiopia
}

\begin{abstract}
Background: Preterm birth has been referring to as babies born alive before 37 weeks' births include medical conditions of the mother or completed weeks or 259 days of gestation of pregnancy are completed. Preterm birth is the leading cause of infant morbidity and mortality throughout the world.

Objective; To assess prevalence and associated factor of preterm births among mother who gave birth at St Paul's Hospital Millennium Medical College, Addis Ababa Ethiopia, 2018.

Methods: Institutional based quantitative cross-sectional study design was conducted in maternity ward and emergency gynecology-obstetrics outpatient department among mothers who gave birth from June 01 -June 20, 2018 at St. Paul's hospital millennium medical college. Data was entered into Epi-info version7 and export into SPSS versions 23.0 for analysis. Bivariate and multivariate logistic regressions were conducted to identify predictors of maternal satisfaction towards childbirth service by considering $\mathrm{p}$-value less than 0.05 .

Result: The study revealed that the prevalence of preterm birth at St. Paul's hospital was $19.8 \%$. The highest contributing maternal factor were history of pregnancy induced hypertension(PIH) and bleeding during pregnancy $(\mathrm{AOR}=4.1395 \% \mathrm{CI}=0.208,7.114)(\mathrm{AOR}=4,00195 \% \mathrm{CI} 1.014,15.795)$ respectively; followed by urinary tract infection (UTI) $(\mathrm{AOR}=2.31195 \% \mathrm{CI} 0.147,6.58)$ which all showed statistically significant association.

Conclusion and recommendation: the higher prevalence of preterm birth of $\sim 20 \%$ was highly associated with most likely preventable or minimal complications causes with regular Antenatal follow up. Pregnant mothers should be regularly screen for PIH, bleeding, UTI \& PROM as it was revealed by the study these factors increased the risk of preterm delivery. In addition, improving maternal healthcare, community health education and awareness campaigns for service utilization may decrease the rate of preterm birth and its consequence.
\end{abstract}

Keywords: Preterm, Maternal, Fetal, neonatal, prevalence

DOI: $10.7176 / \mathrm{JHMN} / 79-02$

Publication date:August $31^{\text {st }} 2020$

\section{Introduction}

Preterm birth is defined as a delivery which occurs at less than 37 completed weeks of gestation. It is classified as extremely preterm ( $<28$ weeks), very preterm ( 28 to $<32$ weeks), and moderate to late preterm ( 32 to $<37$ weeks). Likewise, preterm birth can be categorized on the basis of birth weight. Neonates less than $2500 \mathrm{~g}$ are classified as low birth weight (LBW), $<1500$ g very low birth weight (VLBW) and $<1000$ g extremely low birth weight (ELBW). Preterm birth can also be spontaneous or provider initiated. ${ }^{1}$

The birth of a preterm infant results in significant health consequences to the infant and emotional and economic costs for families and communities. Although advances in prenatal and neonatal care have improved the survival for preterm infants those infants who do survive have a greater risk of developmental disabilities, health, and growth problems than infants born at full term. About $75 \%$ of prenatal deaths and $50 \%$ of neurological abnormalities are directly attributed to preterm. ${ }^{2}$

The majority of preterm birth remains vulnerable to long term complications that may persist all over their lives. Among the main resulting morbidities are neurosensory deficits (blindness, deafness), necrotizing enter colitis, intraventricular hemorrhage, and delay in physical and mental development. According to the report from 'white paper on preterm birth' on 2009, of all 4 million annual early neonatal deaths (deaths within the first 7 days of life) that are non-related to congenital malformations, $28 \%$ are due to preterm birth. ${ }^{3}$ Being born too early is now the leading cause of death in children around the world. Preterm deliveries were responsible for 1 million out of the 6.3 million deaths of children. While the greatest burden is felt in developing countries, it is a problem everywhere. Its negative impacts stretch further when taking into account the health of mothers and the lives of the children who manage to survive. ${ }^{4}$

The complications associated with preterm births are a significant direct cause of death among neonates. Three point one million reported deaths that occur among children globally every year, $35 \%$ of such deaths are as a result of preterm babies. This continues to be the leading most important cause of mortality among children in both developed and developing countries. ${ }^{5}$

The World Health Organization estimates the prevalence of preterm birth to be between 5 and $18 \%$ across 184 countries. Most countries lack reliable data on the burden of preterm birth with only 65 countries having had 
such data in $2010 .^{5}$ Preterm birth is the leading cause of infant morbidity and mortality throughout the world. and the second leading cause of deaths among children under the age of 5 years. Though the particular challenges and burden of preterm birth varies by setting, rates are raising both nationally and globally. It has considerable health, social, psychological and economic consequences. Of the global 135 million live births 14.9 million (11.1\%) babies were born preterm in $2013 .^{6}$

In Ethiopia some studies ${ }^{8,13}$ showed that some risk factors for preterm birth have been identified and included Presence of chronic illness, problem with current pregnancy, PROM, being anemic, low capital wealth index and no ANC follow up were found to be associated with the occurrence of preterm birth in current pregnancy. ${ }^{13}$ Similarly about $12 \%$ of under- five deaths is attributed to preterm birth profile. In number wise 320,000 babies are born too soon each year and 24,000 children under five die due to direct preterm complications.

The aim of this study was to identify common risk factors for preterm birth and its immediate outcome which can indicate the possible means for decreasing both preterm birth occurrence and risk of associated deaths that contributes for the larger neonatal mortality significantly. In our study area there were no previous similar studies. Therefore, the findings of this study could help policy makers, program managers, stake holders, and obstetric care providers to design appropriate interventions to reduce preterm birth and decrease newborn morbidity and mortality. It would help to fill the research gaps in the area and serves as a base line information for similar studies in the country.

\section{Materials and Methods \\ Study Area, Period and Design}

Institution based cross-sectional study was conducted at St Paul's Hospital Millennium Medical College (SPHMMC), Addis Ababa, Ethiopia. The study was conducted on the period between June 1, 2018 to June 30, 2018 to determine magnitude and contribution factor of preterm birth among mothers who gave birth at SPHMMC.

\section{Source Population}

The source population included of all mothers who gave birth at SPHMMC.

\section{Study population}

All women who gave birth with in the time period of June1 to June 30, 2018 at SPHMMC

\section{Sample Size and Sample Size Determination}

Sample size for the study was determined by using single population proportion formula, by taking the proportion of previous study conducted at Jimma University specialized hospital ${ }^{12}(\mathrm{P}=25.9 \%)$, with $\mathrm{CI}=95 \%$, margin of error $=0.05$, a correction formula used to determine the sample size and subsequent adding of $10 \%$ for non-response rate the final sample size $\left(\mathrm{n}_{\mathrm{f}}\right)$ became 237 .

\section{Sampling Technique}

The total number of study subjects was selected through systemic random sampling with $K=N / n, 800 / 237=3.3$ where $\mathrm{N}$ is total number of deliveries in all health institutions during the study period and $\mathrm{n}$ is study population. The first study participant was selected by lottery method, to estimate the total number of deliveries within a data collection time client registration book/record for a month prior to data collection was used and every third $(\mathrm{K}=3)$ delivered mothers involved in the study.

\section{Operational definitions}

- Gestational age: was calculated based on mother's last menstrual period (LMP) or early ultrasound result; when there are extra days it is counted to the near lowest gestational age.

- Preterm birth: being spontaneous preterm (for those which labor was started spontaneously) and indicated (for which labor was induced either for maternal or fetal cases) which is $<37$ weeks of GA.

- Extremely preterm: is preterm birth $<28$ weeks of GA, very preterm is 28 to $<32$ weeks GA and moderate to late preterm is 32 to $<37$ weeks GA as it has been recorded on date of admission.

- Maternal factor: Any history of medical diagnosis in the mother as it has been registered on the medical record.

- Fetal factor: Any recorded medical diagnosis for the preterm neonates on their medical records.

\section{Eligibility Criteria}

\section{- Inclusion criteria}

All women who was admitted to the maternity ward and emergency gyn/obopd and gave birth in the period of June 1 to June 30, 2018.

\section{- Exclusion Criteria}

A woman who delivered at home and recently admitted for retain placenta, post-partum hemorrhage or other complications

Unknown LMP and ultrasound examination was also excluded. 


\section{Data collection instrument}

The data collection instrument was closed-ended questionnaire. Delivery service satisfaction related questions were adopted from the previous studies and presented using three related parts. The first draft of the English questionnaire was translated to Amharic language by independent translators then back to English language to check for consistency.

\section{Data Quality Assurance}

In order to maintain reliability and validity, the questionnaire was pre tested on 24(10\%) postnatal mothers at Addis Ababa university, Tikur Anbessa teaching and referral hospital one month prior to the actual data collection. Findings were discussed among data collectors and supervisor so that, the tool was modified before actual data collection and the final interview was conducted at convenient time using the modified questionnaire. During data collection data was checked by teams and supervisor on daily basis. and corrective measures were taken accordingly.

\section{Data processing and Analysis}

Data was entered into Epi-info version7 and export into SPSS versions 23.0 after checking for completeness then analyzed and expressed using descriptive methods and logistic regression was applied to sort out relationship between variables. Using binary logistic regression variables were identified for having association $(p<0.05)$ with neonatal jaundice and these significant factors were further analyzed with multivariate logistic regressions to find out a statistically significant association.

\section{Ethical Considerations}

Ethical clearance was obtained from St Paul's Hospitals Millennium Medical College Institutional Review Board to conduct the research. Informed oral consent was obtained from each study participant. Confidentiality was assured by making the questionnaire anonymous.

\section{Results}

\section{Socio demographic characteristics of the respondent}

Among 237 samples a total of 237 respondents participated in this study making a response rate of $100 \%$. The mean age $( \pm \mathrm{SD})$ of mothers who gave birth at SPHMMC were $28.30( \pm 4.963)$ which ranged from 17-43 years. The distribution of participants by marital status showed majority of the respondents $225(94.9 \%)$ were married. The distribution of the respondent by educational status indicated that 79 (33.3\%) were Secondary School. level occupational status more than half of participants 126 (53.2\%) were housewives. The mean ( \pm SD) Monthly income were 2725.32 ( $\pm 1611.34 \mathrm{SD})$ Birr. Regarding to house ownership majority of participants $133(56.1 \%)$ live in rental houses (Table 1).

Table 1: Socio-demographic characteristics of mothers who gave birth at SPHMMC in Addis Ababa, Ethiopia $2018(n=237)$

\begin{tabular}{llll}
\hline Study Variable & Response & Frequency (N) & Percent (\%) \\
\hline Age & & & \\
& $15-24$ & 54 & 22.8 \\
& $25-34$ & 149 & 62.9 \\
& $35-44$ & 34 & 14.3 \\
& $>=45$ & 0 & 0 \\
Marital Status & Total & 237 & 100 \\
& Married & 225 & 94.9 \\
& Single & 9 & 3.8 \\
& Widowed & 0 & 0 \\
& Divorced & 3 & 1.3 \\
Educational Status & Total & 237 & 100 \\
& Illiterate & 39 & 16.5 \\
& Read and Write & 27 & 11.4 \\
& Elementary & 49 & 20.7 \\
& Secondary School & 79 & 33.3 \\
& College and Above & 43 & 18.1 \\
& Total & 237 & 100 \\
\hline Ethnic Background Of & Oromo & 111 & 46.8 \\
Respondent & Amhara & 60 & 25.3 \\
& Tigray & 10 & 4.2 \\
& Others & 56 & 23.6 \\
& Total & 237 & 100.0 \\
\hline
\end{tabular}




\begin{tabular}{llll}
\hline Study Variable & & & \\
& & Fesponse & Percent (\%) \\
\hline Religion & Orthodox & 125 & \\
& Muslim & 58 & 52.7 \\
& Protestant & 52 & 24.5 \\
& Others & 2 & 21.9 \\
& Total & 237 & .8 \\
Occupational Status & Un Employee & 7 & 100.0 \\
& House Wife & 126 & 3.0 \\
& Daily Labour & 24 & 53.2 \\
& Merchant & 6 & 10.1 \\
& Gov't /NGO & 38 & 2.5 \\
& PVT Worker & 36 & 16.0 \\
Tevel of family income & Total & 237 & 15.2 \\
& $500-1500$ & 62 & 100 \\
& $1501-2500$ & 71 & 26.2 \\
& $2501-3500$ & 53 & 30.0 \\
& $3501-4500$ & 20 & 22.4 \\
.>4501 & 31 & 8.4 \\
& Total & 237 & 13.1 \\
& Rented & 133 & 100 \\
\hline & Private & 80 & 56.1 \\
& Not Have & 2 & 33.8 \\
& Kebele House & 22 & .8 \\
& Total & 237 & 9.3 \\
& & 100 \\
\hline
\end{tabular}

\section{Prevalence of preterm}

Out of 237 mothers who gave birth at SPHMMC, 47 of them pretty much $20 \%$ (19.83\% to be exact) of babies delivered before 37 weeks of gestation. (Figure 2)
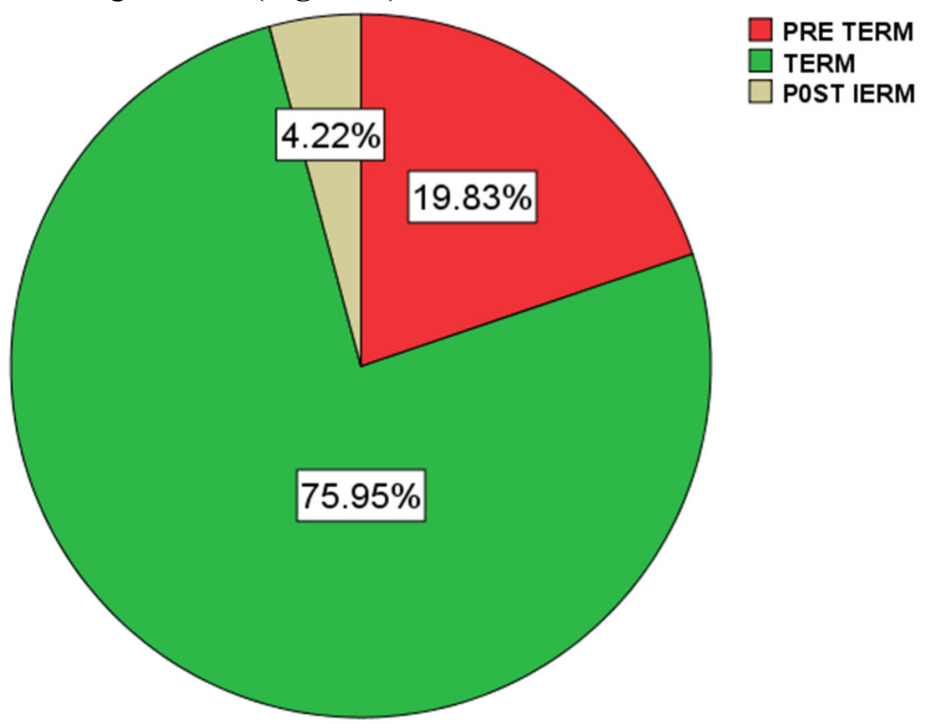

TERM
POST IERM

Figure2: prevalence of Preterm Birth of Mothers Who Gave Birth At SPHMMC In Addis Ababa, Ethiopia $2018(n=237)$

\section{Description of Maternal characteristics}

In descriptive analysis, the study showed that among the total of 237 women who gave birth at SPHMMC, most of the respondents 201(84.1\%) had greater than four visit of ANC. More than one-third of mothers have developed pregnancy induced hypertension followed by PROM and UTI history during pregnancy $(34.2 \%, 32.1 \%, 24.5 \%$ respectively). Close to half mothers were primigravida (46.4\%). Additionally, $12.2 \%$ of mothers had history of preterm birth (Table 2) and (figure 2). 
Table 2: Description of maternal characteristics of the respondents at SPHMMC in Addis Ababa, Ethiopia 2018

\begin{tabular}{|c|c|c|c|}
\hline Study Variable & Response & Frequency $(\mathbf{N})$ & Percent (\%) \\
\hline \multirow{3}{*}{ Spouse Abuse/Domestic Violence } & Yes & 26 & 11.0 \\
\hline & No & 211 & 89.0 \\
\hline & Total & 237 & 100.0 \\
\hline \multirow{4}{*}{ Medication intake during pregnancy } & Yes & 68 & 28.7 \\
\hline & No & 169 & 71.3 \\
\hline & Total & 237 & 100 \\
\hline & Yes & 9 & 3.8 \\
\hline \multirow[t]{2}{*}{ Substance Intake During Pregnancy } & No & 228 & 96.2 \\
\hline & Total & 237 & 100 \\
\hline \multirow[t]{3}{*}{ Mode Of Delivery } & Normal & 111 & 46.8 \\
\hline & $\mathrm{C} / \mathrm{S}$ & 126 & 53.2 \\
\hline & Total & 237 & 100 \\
\hline \multirow[t]{3}{*}{ Gravida } & Primi-gravida & 110 & 46.4 \\
\hline & Multi-gravida & 127 & 53.6 \\
\hline & Total & 237 & 100 \\
\hline \multirow[t]{5}{*}{ Parity } & 0 & 0 & 0 \\
\hline & 1 & 114 & 48.1 \\
\hline & 2 & 80 & 33.8 \\
\hline & $>3$ & 43 & 18.1 \\
\hline & Total & 237 & 100 \\
\hline \multirow[t]{5}{*}{ Birth Interval } & $<1$ year & 2 & .8 \\
\hline & 1-3Years & 86 & 36.3 \\
\hline & $>3$ years & 40 & 16.9 \\
\hline & New & 109 & 46.0 \\
\hline & Total & 237 & 100 \\
\hline \multirow[t]{3}{*}{ History Hyper Emesis Gravid arum } & Yes & 82 & 34.6 \\
\hline & No & 155 & 65.4 \\
\hline & Total & 237 & 100 \\
\hline \multirow{3}{*}{ History Of Abortion } & Yes & 55 & 23.2 \\
\hline & No & 182 & 76.8 \\
\hline & Total & 237 & 100.0 \\
\hline \multirow[t]{3}{*}{ History Of The Still Birth } & Yes & 17 & 7.2 \\
\hline & No & 220 & 92.8 \\
\hline & Total & 237 & 100 \\
\hline \multirow[t]{3}{*}{ History Of Preterm Labor } & Yes & 18 & 7.6 \\
\hline & No & 219 & 92.4 \\
\hline & Total & 237 & 100 \\
\hline \multirow{3}{*}{ History Of Previous C/S } & Yes & 27 & 11.4 \\
\hline & No & 210 & 88.6 \\
\hline & Total & 237 & 100 \\
\hline \multirow{3}{*}{ Pre-Mature Rupture Of Membrane } & Yes & 76 & 32.1 \\
\hline & No & 161 & 67.9 \\
\hline & Total & 237 & 100 \\
\hline \multirow{3}{*}{ History Of Bleeding During Pregnancy } & Yes & 29 & 12.2 \\
\hline & No & 208 & 87.8 \\
\hline & Total & 237 & 100 \\
\hline \multirow[t]{3}{*}{ Urinary Tract Infection During Pregnancy } & Yes & 58 & 24.5 \\
\hline & No & 179 & 75.5 \\
\hline & Total & 237 & 100 \\
\hline \multirow[t]{4}{*}{ Maternal hypertensive disorder } & HTN & 51 & 21.5 \\
\hline & Pre-Eclampsia & 30 & 12.7 \\
\hline & No HTN & 156 & 65.8 \\
\hline & Total & 237 & 100 \\
\hline
\end{tabular}




\begin{tabular}{llll}
\hline Study Variable & Response & Frequency (N) & Percent (\%) \\
\hline History Of DM During Pregnancy & & 14 & 5.9 \\
& Yes & 223 & 94.1 \\
& No & 237 & 100.0 \\
Presence Of Chronic Disease & Total & 40 & 16.9 \\
& Yes & 197 & 83.1 \\
History Of Hospitalization During Pregnancy & No & 237 & 100 \\
& Total & 24 & 10.1 \\
& Yes & 213 & 89.9 \\
History Of ANC Follow Up & To & 237 & 84.8 \\
& Yes & 201 & 15.2 \\
\hline
\end{tabular}

\section{HISTORY OF HYPERTENTION DURING PREGENANCY}

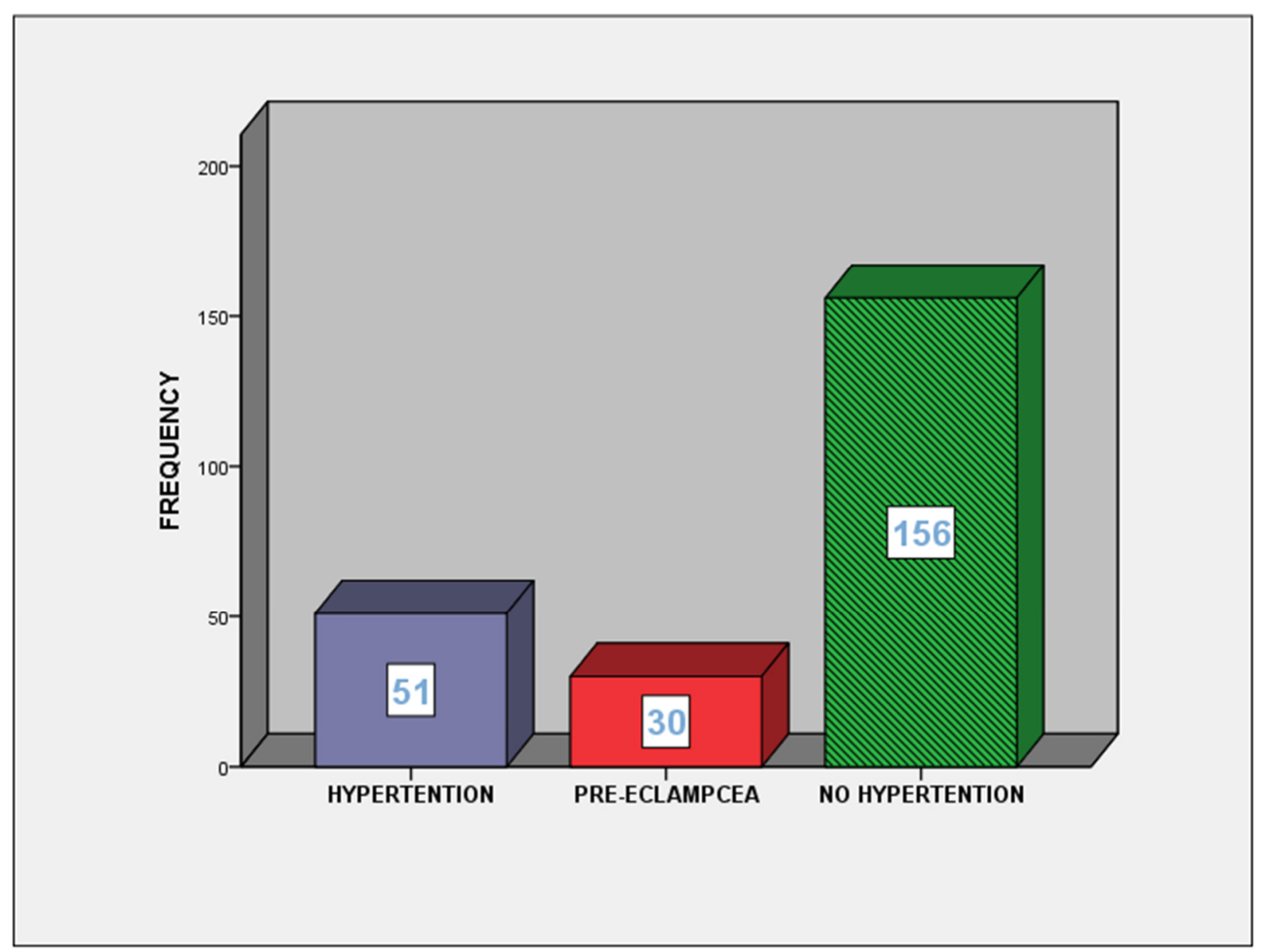

Figure 3: History of hypertension of Mothers/maternal hypertensive disorder/ who gave birth at SPHMMC in Addis Ababa, Ethiopia 2018 (n=237)

\section{Description of Fetal characteristics}

In Descriptive analysis of fetal factors, the study showed that out of 237 alive birth $5.5 \%$ of them have congenital abnormality such as clubfoot spine bifida and Esophageal atresia/tracheoesophageal fistula (EA/TEF) (Table 3). 
Table 3: Description of fetal characteristics of the respondents at SPHMMC in Addis Ababa, Ethiopia 2018

\begin{tabular}{llll}
\hline Study Variable & Response & Frequency (N) & Percent (\%) \\
\hline Congenital Abnormality Of The New Born & Yes & 13 & 5.5 \\
& No & 224 & 94.5 \\
& Total & 237 & 100 \\
History of Twins Delivery Including the & Yes & 8 & 3.4 \\
Current pregnancy & No & 229 & 96.6 \\
& Total & 237 & 100 \\
History Of Congenital Abnormality & Yes & 3 & 1.3 \\
& No & 234 & 98.7 \\
History Of LBW Including the Current & Total & 237 & 100 \\
pregnancy & Yes & 66 & 27.8 \\
& No & 171 & 72.2 \\
\hline
\end{tabular}

\section{Factors associated with preterm birth}

Pre-mature rupture of membrane, history of bleeding, urinary tract infection and maternal hypertensive disorder were included in the final model of analysis for associated factors of preterm birth. The multivariate logistic regression reveled that maternal hypertensive disorder and history of bleeding during pregnancy were the foremost contributor of preterm birth $(\mathrm{AOR}=4.13 ; 95 \% \mathrm{CI}$ 0.208- 7.114) and $(\mathrm{AOR}=4,001$ 95\%CI 1.014-15.795) respectively followed by urinary tract infection during pregnancy (AOR=2.311 95\%CI 0.147-6.58).

TABLE 4: Factors associated with preterm birth among mothers who gave birth at SPHMMC, Addis Ababa, Ethiopia, 2018

\begin{tabular}{|c|c|c|c|c|c|}
\hline \multirow[t]{2}{*}{ VARIABLE } & \multicolumn{2}{|c|}{ PRETERM } & \multirow[t]{2}{*}{ COR(95\%CI) } & \multirow[t]{2}{*}{$\operatorname{AOR}(95 \% C I)$} & \multirow{2}{*}{$\begin{array}{l}\mathbf{P} \\
\text { value }\end{array}$} \\
\hline & Yes & NO & & & \\
\hline \multicolumn{6}{|l|}{$\begin{array}{l}\text { Pre-mature rupture of } \\
\text { membrane }\end{array}$} \\
\hline Yes & $13(5.5 \%)$ & $63(26.6 \%)$ & $1.297(0.640,2.631)$ & $1,261(0.358,2.818) *$ & 0.042 \\
\hline No & $127(53.6 \%)$ & $34(14.3 \%)$ & 0.0 & 0.0 & \\
\hline \multicolumn{6}{|l|}{$\begin{array}{l}\text { History of bleeding } \\
\text { during pregnancy }\end{array}$} \\
\hline Yes & $3(1.3 \%)$ & $26(11 \%)$ & $2.325(0.673,8.039)^{*}$ & $4 . .001(1.014,15.795) *$ & 0.048 \\
\hline No & $164(69 \%)$ & $44(18.6 \%)$ & 0.0 & 0.0 & \\
\hline \multicolumn{6}{|l|}{$\begin{array}{l}\text { Urinary tract } \\
\text { infection during } \\
\text { pregnancy }\end{array}$} \\
\hline Yes & $20(8.4 \%)$ & $38(16 \%)$ & $2.338(0.171,0.669)^{*}$ & $2.311(0.147,0.658)^{* *}$ & 0.002 \\
\hline No & $152(64.2 \%)$ & $27(11.4 \%)$ & 0.0 & 0.0 & \\
\hline \multicolumn{6}{|l|}{ Maternal hypertensive } \\
\hline Yes & $31(13.1 \%)$ & $50(21 \%)$ & $4.126(0.243,1.174)^{* *}$ & $4.133(0.208,7.114)^{* *}$ & 0,009 \\
\hline No & $140(59.1 \%)$ & $16(6.8 \%)$ & 0.0 & 0.0 & \\
\hline
\end{tabular}

*: Significant association at $\mathrm{p}$-value $<\mathbf{0 . 0 5}, * *$ : Significant association at p-value $<0.01$

\section{Discussion}

In this study, prevalence of preterm birth was found to be nearly $20 \%$. This finding was comparable to a study conducted at Jimma university teaching and referral Hospital, which stated that $25.9 \%$ prevalence ${ }^{12}$. This is higher than many others studies outside Ethiopia in South Asia which is $12.8 \%$ of preterm births, $11.8 \%$ in low-income countries, $11.3 \%$ in middle-income countries, 9.4\% upper middle and 9.3\% in high-income countries. ${ }^{9,10}$ It was also higher than a study conducted at Debremarkos Town Health Institutions which stated $11.6 \%{ }^{10}$ Variation of findings with the above studies could be due to the socio-economic difference of the countries and areas, methodological deference as well as the time of study.

The mean age $( \pm \mathrm{SD})$ of mothers who gave birth at SPHMMC was $28.30( \pm 4.963)$ which ranged from 17-43 years. This was similar with other studies ${ }^{9,10,11,12}$ at Debremarkos town (28.57), south Asia (26.7), Gonder (25) and Jimma (25). In rural South Africa and Malawi, significantly greater proportion of women with preterm births was less than 20 years old. ${ }^{15}$ In this study high range of maternal age was seen than most of the studies mentioned, advanced maternal age was stated as one factor for higher proportion of preterm births as it was mentioned in literatures. ${ }^{21}$ 
The study indicated that one of the highest significant associations was found among those who had maternal hypertensive disorder. They were about 4 times more likely to have preterm birth than without those without maternal hypertensive disorder $[\mathrm{AOR}=4.33$ 95\%CI $(0.2087,7.114)]$. This finding was in line with a cross sectional study conducted in Gonder ${ }^{11}$ which was stated that hypertension induced preterm of $\mathrm{AOR}=5.36,95 \% \mathrm{CI}$ $=1.8-15.96$. This comparison might be due to fact that complication of maternal hypertensive disorder could causes preterm birth.

Another major finding of this study was the association of preterm birth and mothers with a history of bleeding during pregnancy. They are also four times more likely to have preterm birth than those who do not have a history of bleeding during pregnancy $[\mathrm{AOR}=4.0095 \% \mathrm{CI}(1.014,15.95)]$. This was supported by a study in Debremarkos ${ }^{10}$ which stated that the likelihood of having preterm birth was about three times higher than those mothers without the problem during their pregnancy $[\mathrm{AOR}=2.9,95 \% \mathrm{CI}=1.3-6.7]$.

Mothers who had urinary tract infection were about two times more likely to had preterm birth (AOR=2.311. $95 \%$ CI $0.147,0.658$ ) than those without UTI. In addition, mothers with premature rupture of membrane had about one-fold higher likelihood of preterm birth than without PROM. Infection may raise release of inflammatory chemokine's and cytokines such as interleukins and tumor necrosis factors. Microbial Endotoxins and pro inflammatory cytokines stimulate the production of prostaglandins (other inflammatory mediators) and matrixdegrading enzymes that finally result in stimulation of uterine contractions, preterm rupture of the membrane, and preterm birth. ${ }^{12}$

\section{Conclusion and recommendation}

Prevalence of Preterm birth was just about $20 \%$. Maternal and fetal factors that highly contributed for preterm birth were identified. Among these factors, maternal factors of maternal hypertensive disorder, history of bleeding during pregnancy, urinary tract infection and premature rupture of membrane showed as a significant association with preterm birth.

So additional efforts of regularly screening of all pregnant mothers for the potential problems, proving quality maternal healthcare, community health information and dissemination campaigns are needed as these contribute for reduction of preterm birth and its consequence in the health of neonates \& mothers in Addis Ababa, Ethiopia. Ministry of Health of Ethiopia in collaboration with all stakeholders should organize efforts to confront the problems. Conducting further researches to identify other possible factors of preterm birth such as fetal causes were recommended.

\section{Acknowledgments}

First of all, I would like to thank almighty God for giving me the strength and patience throughout the study period. I would like to be grateful to my former students Huluagerish Eshete, Mensur Kasim, Kidanmariym Workie for their help during the data collection. Then I would like to express my respect to SPHMMC Administrative, who gave me the permission to proceed and NICU department, for their support in providing all the necessary information. Finally, I would like to be grateful to all who had been supporting me both with idea and logistics.

\section{Disclosure}

The author reports no conflicts of interest in this work.

\section{References}

1. World Health Organization is available on the WHO web site (www.who.int), international statistical classification of disease and related health problem Geneva, Switzerland. 2014

2. Martin JAHB, Sutton PD, Ventura SJ, Menacker F, Kirmeyer Centers for Disease Control and Prevention National Vital Statistics System.S 2007:17

3. Onal REGI, March of Dimes White Paper on Pretermbirth Oll T. 2009

4. http://www.humanosphere.org/global-health/2014/11/dont-knowprevent-new-leading-killer-children/

5. Blencowe H, Cousens S, Chou D, Oestergaard M, Say L, Moller A, et al. Born Too Soon: The global epidemiology of 15 million preterm births. Reproductive Health. 2013:10(Suppl 1):1-14.

6. https://unicefethiopia.wordpress.com preterm-babies-maybe-saved-with-simple-inexpensive-measures

7. Ethiopia profile of preterm and low birth weight prevention and care, http://www.everypreemie.org/wpcontent/uploads/2015/11/Ethiopia

8. Menon R. Preterm birth: a global burden on maternal and child health. Pathogens and Global Health.2012:139-40.

9. P. Steer, "The epidemiology of preterm labour," BJOG: An International Journal of Obstetrics and Gynaecology, vol. 112, supplement 1, pp. 1-3, 2005. oseph KS, Fahey J, Shankardass K, Allen VM, Campo PO, Dodds L, et al. Effects of socioeconomic position and clinical risk factors on spontaneous andiatrogenic preterm birth. BMC Pregnancy and Childbirth. 2014:14(1):1-9. 
10. Bekele T, Amanon A and KahsayGebreslasie Z Preterm Birth and Associated Factors among Mothers Who gave Birth in Debremarkos Town Health Institutions, 2013 BMC.

11. Gebreslasie K. Preterm Birth and Associated Factors among Mothers WhoGave Birth in Gondar Town Health Institutions.2016

12. Bekele I, Demeke T and Dugna K. Prevalence of Preterm Birth and its Associated Factors among Mothers Delivered in Jimma University Specialized Teaching and Referral Hospital, Jimma Zone, Oromia Regional State, South West Ethiopia,2017

13. Barros FC, Bhutta A, Batra M, Hansen TN, Victora CG, Rubens CE. Global report on preterm birth and stillbirth (3 of 7): evidence for effectiveness of interventions. BMC Pregnancy and Childbirth. 2010:10(Relation to Maternal Age. PLOS ONE. 2014:1-16.

14. Broek NR Van Den, Jean-baptiste R, Neilson JP. Factors Associated with Preterm Weng Y, Yang C, Chiu Y. Risk Assessment of Adverse Birth Outcomes in Relation to Maternal Age. PLOS ONE. 2014:1-16

15. Gravett, M. G., Rubens, C. E., \&Nunes, T. M. (2010). Global report on preterm birth and stillbirth ,2010: discovery science:.2010 BMC Pregnancy Childbirth, 10.

16. Reichman, D., Laufer, MR., Robinson, BK. Pregnancy outcomes in unicornuate uteri: a review. Fertility and Sterility. May 2009: Vol. 91, No. 5, pp. 1886-94.

17. Crump, C., Winkleby, M. A., Sundquist, K., \& Sundquist, J. Risk of Hypertension Among Young Adults Who Were Born Preterm: A Swedish National Study of 636,000 Births. American Journal of Epidemiology,2011: 173(7),

18. Clowse, M. E. B., Wallace, D. J., Weisman, M., James, A., Criscione-Schreiber, L. G., \&Pisetsky, D. S. (2013). Predictors of preterm birth in patients with mild systemic.

19. Kent, A. L., Wright, I. M., \& Abdel-Latif, M. E. Mortality and adverse neurologic outcomes are greater in preterm male infants. Paediatrics, 2012:129, 124-131

20. Cochran, w. G.Sampling techniques (3rd ed.). New york: 2012

21. John wiley \& sons. Olugbenga A. Mokuolu BM, Suleiman OO, Adesiyun A, Adeniyi B. Prevalence and determinants of pre-term deliveries in the University of Ilorin Teaching Hospital, Ilorin, Nigeria. Pediatric Report 2010; 2 (3):11-13 